\title{
Quality of Life and Awareness of Cardiac Rehabilitation Program in People With Cardiovascular Diseases
}

\author{
Sehi Kweon, $\mathrm{MD}^{1}$, Min Kyun Sohn, $\mathrm{MD}, \mathrm{PhD}^{1}$, Jin Ok Jeong, $\mathrm{MD}, \mathrm{PhD}^{2}$, Soojae Kim, $\mathrm{MD}^{1}$, \\ Hyunkyu Jeon, $\mathrm{MD}^{1}$, Hyewon Lee, $\mathrm{MD}^{1}$, Seung-Chan Ahn, $\mathrm{MD}^{1}$, Soo Ho Park, MD ${ }^{1}$, Sungju Jee, MD, $\mathrm{PhD}^{1}$
}

Departments of ${ }^{1}$ Rehabilitation Medicine and ${ }^{2}$ Cardiology, Chungnam National University Hospital, Daejeon, Korea

\begin{abstract}
Objective To evaluate the level of health-related quality of life (HRQoL), life satisfaction, and their present awareness of cardiac rehabilitation (CR) program in people with cardiovascular diseases.

Methods A questionnaire survey was completed by 53 patients (mean age, $65.7 \pm 11.6$ years; 33 men and 20 women) with unstable angina, myocardial infarction, or heart failure. The questionnaire included the Medical Outcome Study 36-item Short-Form Health Survey (MOS SF-36), life domain satisfaction measure (LDSM), and the awareness and degree of using CR program.

Results The average scores of physical component summary (PCS) and mental component summary (MCS) were $47.7 \pm 18.5$ and $56.5 \pm 19.5$, respectively. There were significant differences in physical role $(\mathrm{F}=4.2, \mathrm{p}=0.02)$, vitality $(\mathrm{F}=10.7, \mathrm{p}<0.001)$, mental health $(\mathrm{F}=15.9, \mathrm{p}<0.001)$, PCS $(\mathrm{F}=3.6, \mathrm{p}=0.034)$, and $\mathrm{MCS}(\mathrm{F}=11.9, \mathrm{p}<0.001)$ between disease types. The average LDSM score was $4.7 \pm 1.5$. Age and disease duration were negatively correlated with multiple HRQoL areas $(\mathrm{p}<0.05)$. Monthly income, ejection fraction, and LDSM were positively correlated with several MOS SF-36 factors $(\mathrm{p}<0.05)$. However, the number of modifiable risk factors had no significant correlation with medication. Thirty-seven subjects $(69.8 \%)$ answered that they had not previously heard about CR program. Seventeen patients $(32.1 \%)$ reported that they were actively participating in CR program. Most people said that a reasonable cost of CR was less than 100,000 Korean won per month.

Conclusion CR should focus on improving the physical components of quality of life. In addition, physicians should actively promote CR to cardiovascular disease patients to expand the reach of CR program.
\end{abstract}

Keywords Cardiac rehabilitation, Coronary heart disease, SF-36, Quality of life

Received April 28, 2016; Accepted August 24, 2016

Corresponding author: Sungju Jee

Department of Rehabilitation Medicine, Chungnam National University Hospital, 282 Munhwa-ro, Jung-gu, Daejeon 35015, Korea. Tel: +82-42-3382460, Fax: +82-42-338-2461, E-mail: drjeesungju@hanmail.net

ORCID: Sehi Kweon (http://orcid.org/0000-0002-8745-9927); Min Kyun Sohn (http://orcid.org/0000-0002-2548-545X); Jin Ok Jeong (http://orcid. org/0000-0003-0763-4754); Soojae Kim (http://orcid.org/0000-0002-2681-4825); Kyunkyu Jeon (http://orcid.org/0000-0001-6186-2868); Hyewon Lee (http://orcid.org/0000-0003-3105-4071); Seung-Chan Ahn (http://orcid.org/0000-0003-2295-6233); Soo Ho Park (http://orcid.org/0000-0002-18155196); Sungju Jee (http://orcid.org/0000-0002-9400-9609).

(c) This is an open-access article distributed under the terms of the Creative Commons Attribution Non-Commercial License (http://creativecommons.org/ licenses/by-nc/4.0) which permits unrestricted noncommercial use, distribution, and reproduction in any medium, provided the original work is properly cited. Copyright (C) 2017 by Korean Academy of Rehabilitation Medicine 


\section{INTRODUCTION}

Cardiac rehabilitation (CR) is an interdisciplinary team approach to treat patients with functional limitations secondary to heart diseases [1]. The goal of this treatment is to help patients restore their optimal medical, physical, mental, psychological, social, emotional, sexual, vocational, and economic health, all of which are dependent on the severity of disease [1].

It has been reported that CR has beneficial effects $[2,3]$. In a meta-analysis for randomized controlled trials, it has been revealed that participation in exercise-based CR can improve both survival rate and risk factors associated with coronary artery disease [2]. An observational analysis of Medicare Beneficiaries in 1997 has also found a survival benefit associated with participation in CR among patients hospitalized for coronary conditions [3].

Until now, acute coronary syndrome (ACS) management has been focused on reducing mortality and morbidity without considering patient's health-related quality of life (HRQoL). Since the survival rate of ACS patients has increased, HRQoL has become a more important part of ACS management. Many studies have shown that health status, specifically the extent of angina symptoms, strongly predicts long-term clinical outcomes including quality of life of patients with coronary artery disease [46]. In one study, physical limitation has been found to be a significant and independent predictor of 1-year mortality, while angina frequency is a predictor of 1-year ACS readmission [5]. In another study, early primary coronary intervention has provided greater gains in HRQoL compared to conservative therapy mainly due to improvements in angina symptoms [6].

The evaluation of health status through the Medical Outcome Study 36-item Short-Form Health Survey (MOS SF-36) is an assessment tool frequently employed to evaluate HRQoL. MOS SF-36 is a standardized and validated instrument recommended by the American Association of Cardiovascular and Pulmonary Rehabilitation for evaluating HRQoL in patients with cardiovascular disorders [7].

Despite the benefits of CR in myocardial infarction and bypass surgery patients have been widely recognized, participation in and adherence to CR are less than optimal. Previous studies have reported that the rate of participation ranges from $29.5 \%$ to $55 \%$ in the United States
$[8,9]$. In Japan, only $21 \%$ of those with acute myocardial infarction participated in CR [10]. In Australia, only $29 \%$ of those eligible for CR were referred and only one-third of those referred actually attended CR [11]. In Korea, studies on the adherence to or awareness of CR have been rarely reported. One study investigated the reasons why cardiac patients did not participate in CR programs or dropped out [12]. Therefore, the objective of this study was to determine the level of HRQoL, life satisfaction, and their present awareness of CR program in people with cardiovascular diseases.

\section{MATERIALS AND METHODS}

\section{Subjects}

We enrolled patients with cardiovascular diseases who were admitted to the Department of Cardiology and referred for CR. Patients treated between April 2011 and July 2011 were included. Inclusion criteria were: (1) a diagnosis of ACS and heart failure due to ACS, ST elevation myocardial infarction (STEMI), non-ST elevation myocardial infarction (NSTEMI), or unstable angina; (2) admitted in the Department of Cardiology; and (3) referred to the Department of Rehabilitation Medicine for CR. Exclusion criteria were: (1) uncontrolled arrhythmia; (2) peripheral arterial disease; and (3) psychological problems.

\section{Methods \\ General characteristics}

Socioeconomic and demographic characteristics including age, gender, marital status, occupation, familial income, and education were obtained. Marital status was coded as married or not married. Occupation was classified into 16 categories, including no occupation, simple laborer, service manager, technician, office worker, and housewife. In addition, occupational levels were grouped into three categories: no occupation, non-sedentary worker, and sedentary worker. Familial income was classified into five categories in 1 million Korean won increments from $\leq 1,000,000$ to $\geq 4,000,000$ Korean won per month. Education was measured in eight categories, ranging from uneducated to college degree or higher. Educational levels were also grouped into five categories, including uneducated, elementary school diploma, middle school diploma, high school diploma, and college 
degree or higher.

Before inclusion in the study, all patients were asked for informed consent and all agreed to participate.

\section{Clinical characteristics}

Disease status-related clinical variables included major diagnosis, duration, number of medications, type of intervention, the latest left ventricular ejection fraction, the number of modifiable cardiovascular risk factors (hypertension, diabetes mellitus, hyperlipidemia, obesity, smoking, exercise, drinking, stress level), and the degree of participation in the CR program. Clinical data were obtained from clinical records by a single investigator.

\section{Health-related quality of life}

The HRQoL of patients with cardiovascular diseases was assessed with the MOS SF-36 method developed by Ware and Sherbourne [13] in 1992. This is a widely used measure for HRQoL. It has been extensively validated $[14,15]$. The MOS SF-36 consisted of two categories: the physical component summary (PCS) and the mental component summary (MCS). It had eight subcategories. PCS included four subcategories, including physical functioning (PF), physical role (PR), bodily pain (BP), and general medical health (GH). MCS also included four subgroups: vitality (VT), social health ( $\mathrm{SH}$ ), role emotional (RE), and mental health (MH). The MOS SF-36 consisted of these eight subcategories with a total of 35 questions. It also included an additional question about health changes [13]. Summing the item scores from the same scale gave the scale scores in the range from 0 to 100, with higher scores indicating better quality of life [16]. The eight scale scores

Table 1. Demographic characteristics of patients by types of cardiovascular disease

\begin{tabular}{|c|c|c|c|c|}
\hline Characteristic & $\begin{array}{c}\text { All } \\
(n=53)\end{array}$ & $\begin{array}{l}\text { Unstable angina } \\
\qquad(n=24)\end{array}$ & $\begin{array}{l}\text { Myocardial } \\
\text { infarction } \\
(n=17)\end{array}$ & $\begin{array}{l}\text { Heart failure } \\
\qquad(n=12)\end{array}$ \\
\hline Age (yr) & $65.7 \pm 11.6$ & $65.6 \pm 10.5$ & $63.6 \pm 11.6$ & $68.8 \pm 13.9$ \\
\hline \multicolumn{5}{|l|}{ Gender } \\
\hline Male & 33 & 16 & 11 & 6 \\
\hline Female & 20 & 8 & 6 & 6 \\
\hline \multicolumn{5}{|l|}{ Marital status } \\
\hline Married & 40 & 20 & 14 & 6 \\
\hline Single & 13 & 4 & 3 & 6 \\
\hline \multicolumn{5}{|l|}{ Occupation } \\
\hline No occupation & 17 & 9 & 2 & 6 \\
\hline Sedentary worker & 14 & 5 & 7 & 2 \\
\hline Non-sedentary worker & 22 & 10 & 8 & 4 \\
\hline \multicolumn{5}{|c|}{ Monthly familial income (Korean won) ${ }^{\mathrm{a}}$} \\
\hline$\leq 1,000,000$ & $15(34.9)$ & 6 & 5 & 4 \\
\hline $1,000,000-2,000,000$ & $9(20.9)$ & 4 & 4 & 1 \\
\hline $2,000,000-3,000,000$ & $11(25.6)$ & 5 & 4 & 2 \\
\hline $3,000,000-4,000,000$ & $3(7)$ & 1 & 2 & 0 \\
\hline$\geq 4,000,000$ & $5(11.6)$ & 3 & 2 & 0 \\
\hline \multicolumn{5}{|l|}{ Education } \\
\hline Uneducated & 7 & 4 & 1 & 2 \\
\hline Elementary school diploma & 17 & 7 & 4 & 6 \\
\hline Middle school diploma & 6 & 3 & 3 & 0 \\
\hline High school diploma & 9 & 5 & 4 & 0 \\
\hline College degree or higher & 14 & 5 & 5 & 4 \\
\hline
\end{tabular}

Values are presented as mean \pm standard deviation or number (\%).

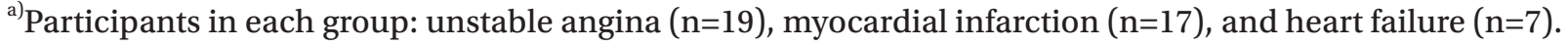


were aggregated into norm-based PCS and MCS scores with a population mean of 50 and a standard deviation of 10.

\section{Life domain satisfaction measure}

The life domain satisfaction measure (LDSM) [17] was used to assess life satisfaction. This measure contained 12 factors covering community, housing, education, employment, leisure, health, financial situation, standard of living, friendship, family relationship, sexual life, and life as a whole. Each question was rated on a 7-point Likerttype scale (from 1 'very dissatisfied' to 7 'very satisfied'), with higher mean scores in each item indicating better satisfaction [17].

\section{Awareness of cardiac rehabilitation program}

The awareness and degree of acceptance of CR were also investigated in this study. The questionnaire included awareness of and intention to participate in CR, cost, and location of CR.

\section{Statistical analysis}

Statistical analyses were performed using PASW ver. 18.0 for Windows (SPSS Inc., Chicago, IL, USA). All calculated $\mathrm{p}$-values were two-sided. Statistically significance was considered when p-value was less than 0.05. Categorical data are expressed as number (\%). Continuous variables are expressed as mean \pm standard deviation. Mean scores from MOS SF-36 were compared among diagnoses using one-way analysis of variance (ANOVA) followed by post-hoc analyses. Pearson correlation analysis was performed to determine the association among socioeconomic, clinical status, and HRQoL factors.

\section{RESULTS}

\section{Demographic and clinical characteristics}

Of the 65 participants, 53 patients met the inclusion criteria, including 33 males and 20 females. Data of the 53 patients were analyzed. Their mean age was 65.7 years (range, 38-86 years) (Table 1). Most patients (75.5\%) were married. Of the 53 patients, 17 (32.1\%) had graduated from elementary school. Forty-three patients responded to questions about monthly family income-15 (34.9\%) earned less than 1,000,000 Korean won, 9 (20.8\%) earned 1,000,000-2,000,000 Korean won, 11 (25.6\%) earned 2,000,000-3,000,000 Korean won, 3 (7\%) earned 3,000,000-4,000,000 Korean won, and 5 (11.6\%) earned more than 4,000,000 Korean won (Table 1). For occupation area, $45.5 \%$ were manual workers, $32.1 \%$ had no occupation, and $26.4 \%$ were sedentary workers (Table 1 ). There were no significant differences in socioeconomic characteristics among the three types of cardiovascular diseases. Twenty-four (45.3\%), 16 (32.1\%), and 12

Table 2. Clinical characteristics of patients by types of cardiovascular disease

\begin{tabular}{|lcccc}
\hline \multicolumn{1}{c}{ Characteristic } & All & Unstable angina & $\begin{array}{c}\text { Myocardial } \\
\text { infarction }\end{array}$ & Heart failure \\
\hline Number of patients & $53(100)$ & $24(45.3)$ & $16(32.1)$ & $12(22.6)$ \\
\hline Disease duration (mo) & $29.4 \pm 61.9$ & $29.5 \pm 57.4$ & $13.1 \pm 37.9$ & $52.5 \pm 90.4$ \\
\hline Number of drugs & $6.2 \pm 2.9$ & $4.9 \pm 2.4^{*}$ & $7.1 \pm 3.0$ & $7.4 \pm 3.2$ \\
\hline Intervention & & & & \\
\hline PCI & $14(26.4)$ & $3(5.7)$ & $10(18.9)$ & $1(1.9)$ \\
\hline Pacemaker & $2(3.8)$ & $0(0)$ & $0(0)$ & $2(3.8)$ \\
\hline CABG & $2(3.8)$ & $0(0)$ & $2(3.8)$ & $0(0)$ \\
Valve replacement & $1(1.9)$ & $0(0)$ & $0(0)$ & $1(1.9)$ \\
\hline Modifiable cardiovascular risk factor & $2.9 \pm 1.6$ & $2.9 \pm 1.4$ & $3.0 \pm 1.9$ & $3.2 \pm 1.7$ \\
\hline LVEF (\%) & $54.5 \pm 13.7$ & $59.9 \pm 7.9$ & $53.8 \pm 11.7$ & $44.4 \pm 19.4^{*}$ \\
\hline Participation on CR & $10(18.9)$ & $3(5.7)$ & $5(9.4)$ & $2(3.8)$ \\
\hline
\end{tabular}

Values are presented as number (\%) or mean \pm standard deviation.

PCI, percutaneous coronary intervention; CABG, coronary artery bypass graft; LVEF, left ventricular ejection fraction; $\mathrm{CR}$, cardiac rehabilitation.

${ }^{*} \mathrm{p}<0.05$. 
(22.6\%) patients were diagnosed with unstable angina (UA), myocardial infarction (MI), and heart failure (HF), respectively. The average duration of the disease was $29.4 \pm 61.9$ months. The average number of drugs taken by patients was $6.2 \pm 2.9$. The mean number of modifiable cardiovascular risk factors was $2.9 \pm 1.6$. The mean LVEF was $54.5 \% \pm 13.7 \%$ (Table 2). The number of drugs taken $(\mathrm{F}=4.560, \mathrm{p}=0.015)$ and $\operatorname{LVEF}(\mathrm{F}=4.550, \mathrm{p}=0.017)$ were significantly different among the three types of cardiovascular diseases. Scheffe post-hoc analysis revealed that both drug number $(\mathrm{p}<0.05)$ and LVEF $(\mathrm{p}=0.022)$ were significantly different between the unstable angina group and the heart failure group.
Quality of life and life domain satisfaction measures

The average MOS SF-36 PCS score was $47.7 \pm 18.5$ and the average MCS score was $56.5 \pm 19.5$. In disease group analysis, the PCS scores of UA, MI, and HF were 51.2 \pm $17.9,51.2 \pm 18.0$, and $35.6 \pm 16.6$, respectively. They were significantly different among disease groups ( $\mathrm{F}=3.62$, $\mathrm{p}=0.03$ ) by ANOVA. However, post-hoc analysis did not reveal any significant difference among groups. Disease group analysis revealed that the MCS scores of UA, MI, and $\mathrm{HF}$ were $57.7 \pm 15.7,67.9 \pm 15.8$, and $37.8 \pm 18.4$, respectively, which were significantly different $(\mathrm{F}=12.0, \mathrm{p}<0.001)$ based on ANOVA. Scheffe post-hoc analysis revealed that the HF group had significantly lower MCS score than the MI group $(\mathrm{p}<0.001)$ and the UA group $(\mathrm{p}=0.005)$. Each MOS SF-36 factor including PR ( $\mathrm{F}=4.2, \mathrm{p}=0.02)$, VT

Table 3. MOS SF-36 scores according by cardiovascular disease type

\begin{tabular}{|c|c|c|c|c|}
\hline & All patients & Unstable angina & $\begin{array}{l}\text { Myocardial } \\
\text { infarction }\end{array}$ & Heart failure \\
\hline PCS & $47.7 \pm 18.5$ & $51.2 \pm 17.9$ & $51.2 \pm 18.0$ & $35.6 \pm 16.6^{*}$ \\
\hline Physical functioning (PF) & $48.9 \pm 32.3$ & $52.3 \pm 32.2$ & $54.1 \pm 33.9$ & $34.6 \pm 28.2^{*}$ \\
\hline Role physical (RP) & $52.4 \pm 32.3$ & $56.8 \pm 30.4$ & $61.8 \pm 29.7$ & $30.2 \pm 31.6^{*}$ \\
\hline Bodily pain (BP) & $43.6 \pm 22.5$ & $50.0 \pm 17.7$ & $43.5 \pm 25.2$ & $30.8 \pm 23.5^{*}$ \\
\hline General health (GH) & $44.7 \pm 5.0$ & $46.3 \pm 5.8$ & $43.5 \pm 4.2$ & $43.3 \pm 3.9$ \\
\hline MCS & $56.5 \pm 19.5$ & $57.7 \pm 15.7$ & $67.9 \pm 15.8$ & $37.8 \pm 18.4^{*}$ \\
\hline Vitality (VT) & $38.6 \pm 22.5$ & $42.2 \pm 20.2$ & $48.5 \pm 18.0$ & $17.2 \pm 16.5^{*}$ \\
\hline Social functioning (SF) & $63.2 \pm 30.2$ & $62.0 \pm 29.1$ & $75.0 \pm 25.4$ & $49.0 \pm 33.9$ \\
\hline Role emotional (RE) & $64.3 \pm 30.3$ & $64.2 \pm 30.8$ & $74.5 \pm 27.2$ & $50.0 \pm 29.7$ \\
\hline Mental health (MH) & $63.4 \pm 20.1$ & $64.6 \pm 15.8$ & $76.5 \pm 13.0$ & $42.5 \pm 20.1^{*}$ \\
\hline LDSM & $4.1 \pm 0.9$ & $4.1 \pm 1.0$ & $4.5 \pm 0.7$ & $3.5 \pm 0.4$ \\
\hline Community & $4.3 \pm 1.4$ & $4.4 \pm 1.2$ & $4.4 \pm 1.6$ & $4.1 \pm 1.4$ \\
\hline Housing & $4.8 \pm 1.5$ & $4.7 \pm 1.6$ & $5.3 \pm 1.2$ & $4.1 \pm 1.5$ \\
\hline Education & $3.9 \pm 1.8$ & $3.9 \pm 1.8$ & $4.5 \pm 1.8$ & $3.1 \pm 1.7$ \\
\hline Employment & $2.4 \pm 2.5$ & $2.3 \pm 2.5$ & $3.4 \pm 2.5$ & $1.2 \pm 2.0$ \\
\hline Leisure & $4.0 \pm 1.7$ & $4.0 \pm 1.6$ & $4.0 \pm 2.0$ & $3.9 \pm 1.4$ \\
\hline Health & $2.9 \pm 1.6$ & $3.2 \pm 1.7$ & $3.1 \pm 1.6$ & $2.1 \pm 1.2$ \\
\hline Financial situation & $4.0 \pm 1.4$ & $4.0 \pm 1.6$ & $4.3 \pm 1.2$ & $3.5 \pm 1.2$ \\
\hline Standard of living & $4.5 \pm 1.2$ & $4.8 \pm 1.3$ & $4.5 \pm 0.9$ & $3.8 \pm 1.1$ \\
\hline Friendship & $5.0 \pm 1.3$ & $4.8 \pm 1.3$ & $5.4 \pm 1.2$ & $4.9 \pm 1.0$ \\
\hline Family relationship & $5.3 \pm 1.4$ & $4.9 \pm 1.7$ & $5.8 \pm 1.0$ & $5.5 \pm 1.2$ \\
\hline Sexual life & $3.9 \pm 2.1$ & $4.2 \pm 1.7$ & $4.5 \pm 1.8$ & $2.3 \pm 2.4$ \\
\hline Life as a whole & $4.8 \pm 1.5$ & $4.7 \pm 1.5$ & $5.3 \pm 1.0$ & $4.1 \pm 1.8$ \\
\hline
\end{tabular}

Values are presented as mean \pm standard deviation.

MOS SF-36, medical outcome study short-form 36-item; PCS, physical component summary; MCS, mental component summary; LDSM, life domain satisfaction measure.

${ }^{*} \mathrm{p}<0.05$. 
$(\mathrm{F}=10.7, \mathrm{p}<0.001), \mathrm{MH}(\mathrm{F}=15.9, \mathrm{p}<0.001), \mathrm{PCS}(\mathrm{F}=3.6$, $\mathrm{p}=0.034)$, and MCS $(\mathrm{F}=11.9, \mathrm{p}<0.001)$ showed significant differences among disease groups. The RP score in the HF group was lower $(p=0.03)$ than that in the UA group. VT in the HF group was lower than that in the UA group $(\mathrm{p}=0.002)$ and the MI group $(\mathrm{p}<0.001)$. MH in the HF was also lower than that in the UA group $(\mathrm{p}<0.001)$ and the MI group ( $\mathrm{p}<0.001)$ (Table 3$)$.

The life satisfaction score was $4.7 \pm 1.5$, which was above the 'moderate' score. However, there was no significant difference among disease groups $(\mathrm{F}=2.6, \mathrm{p}=0.09)$ (Table 3 ).

Correlation between quality of life and cardiac disease

Pearson correlation analysis revealed that older age and female gender were correlated with worse statuses of several MOS SF-36 factors, including PCS $(\gamma=-0.487$, $\mathrm{p}<0.001), \operatorname{PF}(\gamma=-0.483, \mathrm{p}<0.001), \operatorname{RP}(\gamma=-0.451, \mathrm{p}<0.001)$, PF $(\gamma=-0.283, p<0.05)$, and RE $(\gamma=-0.274, p<0.05)$. Marriage and education were correlated with better PCS $(\gamma=$ $0.417, \mathrm{p}<0.001)$, PF $(\gamma=0.412, \mathrm{p}<0.001)$, and RP $(\gamma=0.359$, $\mathrm{p}<0.001)$. Monthly income was significantly associated with higher SF-36 scores, including PCS, MCS, PF, RP, BP, and VT. Older age, being female, single, lower educational level, lower income, and harder work were associated with low HRQoL scores (Table 4).

Disease duration was significantly $(\mathrm{p}<0.05)$ associated with lower PCS $(\mathrm{r}=-0.396), \operatorname{MCS}(\mathrm{r}=-0.316), \operatorname{PF}(\gamma=$ $-0.385), \operatorname{RP}(\gamma=-0.313)$, and VT $(\gamma=-0.310)$ scores. LVEF was positively $(\mathrm{p}<0.05)$ correlated with PCS $(\gamma=0.337)$, PF $(\gamma=0.286)$, RP $(\gamma=0.299)$, GH $(\gamma=0.276)$, and VT $(\gamma=0.274)$. Pearson correlation analysis revealed that disease duration and LVEF were associated with low HRQoL scores (Table 4).

\section{Awareness of cardiac rehabilitation program}

A total of 16 patients $(30.2 \%)$ indicated that they had heard about a CR program. Of these 16 subjects, 14 (87.5\%) reported that the person who introduced them to CR program was a doctor.

After explaining the CR program, we asked patients about their intention to participate in such program. Seventeen (32.1\%) patients indicated that they would actively participate, $19(35.8 \%)$ indicated that they might participate, $13(24.5 \%)$ said that they might not participate, and $4(7.5 \%)$ indicated that they would never participate. We asked these patients about barriers to participation

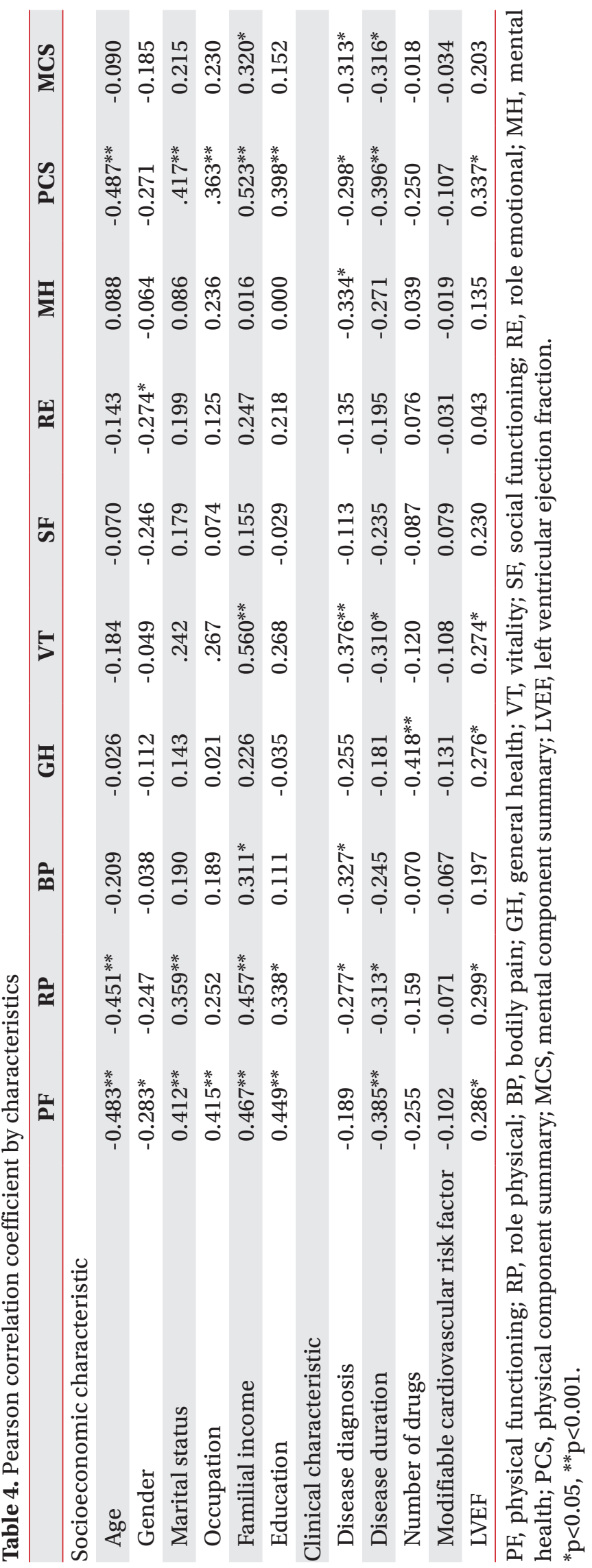

www.e-arm.org 
and 23 of the 53 subjects responded. The most common barrier was distance (35.3\%). Lack of time was the second most common barrier (23.5\%). Almost all subjects (92.5\%) selected below 100,000 Korean won as a reasonable cost for a monthly CR program. A total of $35.8 \%$ of patients reported that university hospital was the most convenient place to participate in the CR program (Table 5).

\section{DISCUSSION}

In this study, we determined the characteristics of patients admitted for cardiovascular diseases. For HRQoL, patients with heart failure due to ACS were affected more than those with just acute coronary syndrome. The overall life satisfaction of cardiac disease patients was slightly higher than that of the general population. Several MOS SF-36 factors were significantly correlated with age, gender, marriage, education level, monthly income, occupation level, disease duration, and LVEF. LDSM had a significant correlation with HRQoL. However, it had no significant correlation with patient characteristics.

Various studies on patients with heart diseases have revealed that age is a predictive factor for HRQoL, particularly after percutaneous myocardial revascularization or MI [18-20]. Previous studies have demonstrated that age is a common predictor for the quality of life using MOS SF-36 MCS and PCS measures [18]. In addition, baseline PCS and MCS scores are independent predictors of follow-up PCS and MCS scores [18]. Older patients in CR programs have shown less ability to perform daily activities, which by itself can affect their perception of HRQoL [21]. At the same time, data from the literature suggest that older patients are less likely to receive more aggressive treatment $[22,23]$. In this study, advanced age was associated with worse perception of physical quality of life, although it was not an independent predictor.

Another variable associated with HRQoL was the sex of the patient, with females being more predisposed to having lower PF and RE scores. Soto et al. [24] have also investigated HRQoL in coronary patients and found that females have worse physical dimension scores than males, particularly for PF. They suggested that this might be due to lower morbidity levels and worse CHD-related recovery in females [24]. Van Jaarsveld et al. [25] have shown that females constitute a vulnerable group with more physical limitations, more distress, and more social
Table 5. Awareness of cardiac rehabilitation (CR) program

\begin{tabular}{|c|c|}
\hline & No. (\%) \\
\hline \multicolumn{2}{|l|}{ Heard about CR program } \\
\hline No & $37(69.8)$ \\
\hline Yes & $16(30.2)$ \\
\hline \multicolumn{2}{|c|}{ Information source for CR program $(\mathrm{n}=16)$} \\
\hline Doctor & $14(26.4)$ \\
\hline Ward nurse & $1(1.9)$ \\
\hline Education nurse & $1(1.9)$ \\
\hline Friend & $0(0)$ \\
\hline \multicolumn{2}{|l|}{ Intention to participate } \\
\hline Actively participate & $17(32.1)$ \\
\hline Participate & $19(35.8)$ \\
\hline May not & $13(24.5)$ \\
\hline Never & $4(7.5)$ \\
\hline \multicolumn{2}{|l|}{ Barrier to participation $(\mathrm{n}=17)$} \\
\hline Cost & $2(11.8)$ \\
\hline Distance & $6(35.3)$ \\
\hline Doubt about effect & $1(5.9)$ \\
\hline Lack of time & $4(23.5)$ \\
\hline No need & $1(5.9)$ \\
\hline Poor physical condition & $2(11.8)$ \\
\hline Discomfort of moving & $0(0)$ \\
\hline Anxiety & $0(0)$ \\
\hline Being able to perform at home & $1(5.9)$ \\
\hline \multicolumn{2}{|l|}{ Total cost of CR (Korean won) } \\
\hline$<10,000$ & $25(47.2)$ \\
\hline $10,000-100,000$ & $24(45.3)$ \\
\hline $100,000-500,000$ & $4(7.5)$ \\
\hline $500,000-1,000,000$ & $0(0)$ \\
\hline $100,000-3,000,000$ & $0(0)$ \\
\hline \multicolumn{2}{|l|}{ Place for CR } \\
\hline University hospital & $19(35.8)$ \\
\hline Hospital & $14(26.4)$ \\
\hline Clinic & $7(13.2)$ \\
\hline Public local health center & $10(18.9)$ \\
\hline Health care facility & $3(5.7)$ \\
\hline
\end{tabular}

limitations than males. Women also had lower score in emotional factors compared to men in our study. This suggests that women with coronary heart disease might have been affected by low levels of physical activity and mental factors, thus affecting their quality of life.

Awareness of the CR program was very low (30.2\%). The 
majority of patients who had heard about it had been informed by a physician (87.5\%). A total of $67.9 \%$ of patients indicated that they would participate in $\mathrm{CR}$, while only $18.9 \%$ of patients actually participated. This suggests that improving the awareness of CR program is very important. In addition, the difference between those who wish to participate in CR and the number of those who actually do so suggests that there are some barriers to participating in the CR program. Kim et al. [12] have reported that the most common cause of low participation is the lack of awareness. Having doubt about its effect and poor physical condition are also often-cited reasons. This study also suggest that the awareness of CR program is not high among people with cardiovascular diseases and that non-physician medical professionals have little idea about the availability of CR program. The most common reasons cited for not participating were distance, lack of time, and financial problems. To improve participation in CR program, further studies are needed to determine the barriers to CR participation.

Almost all patients indicated that appropriate cost for monthly CR was less than 100,000 Korean won (92.5\%). Jolly et al. [26] have reported that the cost of hospitalcentered CR is $£ 486$ per course. Marchionni et al. [27] have reported that direct cost (in US $\$ 2,000$ ) calculated as the sum of CR program cost $(\$ 8,841)$ and healthcare utilization cost $(\$ 12,457)$ over the study duration is $\$ 21,298$ for hospital-based CR. Given these findings, the monthly cost preferred by patients in this study was well below the average cost for CR. The most commonly cited location for CR was in a hospital (62.2\%). However, Jolly et al. [26] have shown that PCS and MCS scores after 6-12 weeks of hospital-based CR and after 18 weeks of home-based CR are not significantly different. In contrast, Arthur et al. [28] and Smith et al. [29] have reported that PCS scores are higher after home-based CR. The location of CR can be a barrier to participation in CR. CR outcome may vary by location. Therefore, further studies are needed to determine the effectiveness of $\mathrm{CR}$ in different locations.

In conclusion, results of this study suggest that $\mathrm{CR}$ program needs to focus on factors associated with HRQoL. In addition, the awareness of CR program is still too low. Therefore, physicians need to improve their communication about the availability of CR program. Information obtained from this study can be used to determine appropriate ways to increase participation in CR programs in the future for patients with cardiovascular diseases.

\section{CONFLICT OF INTEREST}

No potential conflict of interest relevant to this article was reported.

\section{ACKNOWLEDGMENTS}

This study was supported by a grant (HI13C-1990010015) of the Translational R\&D Project funded by Korea Health Industry Development Institute, Republic of Korea.

\section{REFERENCES}

1. Whiteson JH, Einarsson G. Cardiac rehabilitation. In: Braddom RL, editor. Physical medicine and rehabilitation. 4th ed. Philadelphia: Saunders; 2011. p. 71340.

2. Taylor RS, Brown A, Ebrahim S, Jolliffe J, Noorani H, Rees $\mathrm{K}$, et al. Exercise-based rehabilitation for patients with coronary heart disease: systematic review and meta-analysis of randomized controlled trials. Am J Med 2004;116:682-92.

3. Suaya JA, Stason WB, Ades PA, Normand SL, Shepard DS. Cardiac rehabilitation and survival in older coronary patients. J Am Coll Cardiol 2009;54:25-33.

4. Spertus JA, Salisbury AC, Jones PG, Conaway DG, Thompson RC. Predictors of quality-of-life benefit after percutaneous coronary intervention. Circulation 2004;110:3789-94.

5. Spertus JA, Jones P, McDonell M, Fan V, Fihn SD. Health status predicts long-term outcome in outpatients with coronary disease. Circulation 2002;106:439.

6. Kim J, Henderson RA, Pocock SJ, Clayton T, Sculpher MJ, Fox KA, et al. Health-related quality of life after interventional or conservative strategy in patients with unstable angina or non-ST-segment elevation myocardial infarction: one-year results of the third Randomized Intervention Trial of unstable Angina (RITA3). J Am Coll Cardiol 2005;45:221-8.

7. Uchmanowicz I, Loboz-Grudzien K, Jankowska-Polanska B, Sokalski L. Influence of diabetes on healthrelated quality of life results in patients with acute 
coronary syndrome treated with coronary angioplasty. Acta Diabetol 2013;50:217-25.

8. Centers for Disease Control and Prevention. Receipt of cardiac rehabilitation services among heart attack survivors: 19 states and the District of Columbia, 2001. MMWR Morb Mortal Wkly Rep 2003;52:1072-5.

9. Witt BJ, Jacobsen SJ, Weston SA, Killian JM, Meverden RA, Allison TG, et al. Cardiac rehabilitation after myocardial infarction in the community. J Am Coll Cardiol 2004;44:988-96.

10. Goto Y, Itoh H, Adachi H, Ueshima K, Nohara R. Use of exercise cardiac rehabilitation after acute myocardial infarction. Circ J 2003;67:411-5.

11. Scott IA, Lindsay KA, Harden HE. Utilisation of outpatient cardiac rehabilitation in Queensland. Med J Aust 2003;179:341-5.

12. Kim C, Lim HS, Ahn JK, Bang IK, Lee SM, Kim YJ. The reasons that cardiac patients did not participate in and drop out from the cardiac rehabilitation program. J Korean Acad Rehabil Med 2002;26:790-6.

13. Ware JE Jr, Sherbourne CD. The MOS 36-item shortform health survey (SF-36). I: Conceptual framework and item selection. Med Care 1992;30:473-83.

14. Hays RD, Shapiro MF. An overview of generic healthrelated quality of life measures for HIV research. Qual Life Res 1992;1:91-7.

15. Ware JE Jr. The status of health assessment 1994. Annu Rev Public Health 1995;16:327-54.

16. Ware JE, Kosinski MA, Dewey JE. How to score version 2 of the SF-36 Health Survey. Lincoln: Quality Metric Inc.; 2000.

17. Campbell A, Comverse PE, Rodgers WL. The quality of American life: perceptions, evaluations, and satisfactions. New York: Russel Sage Foundation; 1976. p. 519-64.

18. Nash IS, Curtis LH, Rubin H. Predictors of patientreported physical and mental health 6 months after percutaneous coronary revascularization. Am Heart J 1999;138(3 Pt 1):422-9.

19. Veenstra M, Pettersen KI, Rollag A, Stavem K. Association of changes in health-related quality of life in coronary heart disease with coronary procedures and sociodemographic characteristics. Health Qual Life Outcomes 2004;2:56.

20. Heller RF, Lim L, Valenti L, Knapp J. Predictors of quality of life after hospital admission for heart attack or angina. Int J Cardiol 1997;59:161-6.

21. Trzcieniecka-Green A, Steptoe A. Stress management in cardiac patients: a preliminary study of the predictors of improvement in quality of life. J Psychosom Res 1994;38:267-80.

22. Pilote L, Miller DP, Califf RM, Rao JS, Weaver WD, Topol EJ. Determinants of the use of coronary angiography and revascularization after thrombolysis for acute myocardial infarction. N Engl J Med 1996;335: 1198-205.

23. Goldberg RJ, McCormick D, Gurwitz JH, Yarzebski J, Lessard D, Gore JM. Age-related trends in short- and long-term survival after acute myocardial infarction: a 20-year population-based perspective (1975-1995). Am J Cardiol 1998;82:1311-7.

24. Soto M, Failde I, Marquez S, Benitez E, Ramos I, Barba A, et al. Physical and mental component summaries score of the SF-36 in coronary patients. Qual Life Res 2005;14:759-68.

25. van Jaarsveld CH, Sanderman R, Ranchor AV, Ormel J, van Veldhuisen DJ, Kempen GI. Gender-specific changes in quality of life following cardiovascular disease: a prospective study. J Clin Epidemiol 2002;55: 1105-12.

26. Jolly K, Taylor R, Lip GY, Greenfield S, Raftery J, Mant J, et al. The Birmingham Rehabilitation Uptake Maximisation Study (BRUM). Home-based compared with hospital-based cardiac rehabilitation in a multi-ethnic population: cost-effectiveness and patient adherence. Health Technol Assess 2007;11:1-118.

27. Marchionni N, Fattirolli F, Fumagalli S, Oldridge N, Del Lungo F, Morosi L, et al. Improved exercise tolerance and quality of life with cardiac rehabilitation of older patients after myocardial infarction: results of a randomized, controlled trial. Circulation 2003; 107:2201-6.

28. Arthur HM, Smith KM, Kodis J, McKelvie R. A controlled trial of hospital versus home-based exercise in cardiac patients. Med Sci Sports Exerc 2002;34:154450 .

29. Smith KM, Arthur HM, McKelvie RS, Kodis J. Differences in sustainability of exercise and health-related quality of life outcomes following home or hospitalbased cardiac rehabilitation. Eur J Cardiovasc Prev Rehabil 2004;11:313-9. 